Página inicial: 603 - Página final: 622

Tipo de artículo: de Reflexión derivada de investigación

\title{
Presencia Franciscana en las Universidades durante los Siglos XIII y XIV.
}

Franciscan Presence in the Universities during the XIII and XIV Centuries.

Recibido: enero 2016 Revisado: abril 2016 Aceptado: mayo 2016

Por: Jaime Caiceo Escudero. ${ }^{1}$

\section{Resumen.}

Se presentan insumos de análisis que aportan en el reconocimiento del origen de la filosofia franciscana, sus principales exponentes europeos y su incursión en los centros educacionales superiores en el siglo XIII, resaltando su aporte a la ciencia y a la configuración del pensamiento moderno.

\section{Palabras claves.}

Filosofia Franciscana, educación, modernidad.

\begin{abstract}
.
Inputs from analyses, which provide recognition of the origin of the Franciscan philosophy, its main European exponents, and its incursion into educational universities in the 13th century, highlighting its contribution to science and to the configuration of modern thought, are presented
\end{abstract}

\section{Key words.}

Franciscan Philosophy, Education, Modernity.

1 Académico de la Universidad de Santiago de Chile y Director del Colegio Franciscano Santa Isabel de Hungría en La Cisterna, Santiago de Chile. Correo: jcaiceo@hotmail.com. 


\section{Introducción.}

San Francisco de Asís fundó la Orden de Hermanos o Frailes Menores (O.F.M.) en 1208, por inspiración divina. Perteneciendo a una familia rica, deja todo en 1205 y se dedica a una vida austera y a predicar el Evangelio; rápidamente tiene seguidores, siendo los tres primeros Bernardo de Quintavalle, Pedro Cattani y Gil de Asís; a ellos y a los que seguirán, los envía en misión a predicar y practicar en su vida diaria el Evangelio (Directorio Franciscano, 2013) de esta forma, los frailes hacian sus labores diarias atendiendo a los más pobres y abandonados de la época, los leprosos; trabajando en faenas humildes para los monasterios, casas particulares y prestando sus servicios para granjeros en los campos. Al año siguiente (1209) va a Roma con sus seguidores, que ya eran 11 , a solicitarle al Papa Inocencio III la aprobación de la primera regla de la Orden; después de dos intentos consiguió que se la aprobara verbalmente, al convencerse Su Santidad de que la ayuda de un hombre como Francisco reforzaria la imagen de la Iglesia -deteriorada en ese entoncescon su prédica y su práctica del Evangelio; de esta forma, además, fue aceptada en la Iglesia su hermandad de pobres, llamada Orden de Hermanos Menores (Ordinis Fratrum Minorum, O.F.M.). De regreso a Asís se instalan en Río Torto y, a partir del año siguiente, se trasladan a un terreno adyacente a la capilla de la Porciúncula.

Siguiendo su premisa de evangelización intenta varias veces ir a oriente (Siria en 1212, Marruecos en 1214, Egipto en 1219) sin mucho éxito, salvo en el último viaje en que se hace amigo del Sultán Mélek-el-Kamel; había ido a San Juan de Acre y Damieta, lugares en ruta a Jerusalén hacia donde iban los Cruzados; él deseaba evangelizar a los musulmanes a fin de rescatar el Santo Sepulcro sin armas de guerra sino que con las armas del amor y del testimonio de pobreza (Directorio Franciscano: San Francisco de Asís, 2013).

Este espíritu misionero posibilitó que los lugares sagrados de Tierra Santa sean resguardados, aún hoy, por la Orden de Hermanos Menores, pues ellos fueron admitidos por los árabes, gracias al Sultán amigo. Incluso, según las Florecillas, el Sultán "concedió a Francisco y a sus compañeros que pudiesen predicar libremente donde quisieran. Y les dio una contraseña a fin de que no fuesen molestados de nadie" (Joergensen, 1913, p. 126). Esta situación se vio reforzada con la Bula del Papa Gregorio IX -antiguo amigo de Francisco- del $1^{\circ}$ de febrero de 1230 en que recomienda a los Patriarcas de Antioquía y Jerusalén, a los Legados de la Santa Sede y a todos los Arzobispos, Obispos, Abades, Priores, Superiores y otros, acoger y favorecer de todos los modos posibles a la Orden de los Hermanos Menores para que ellos resguardaran los lugares sagrados de la mejor forma posible, puesto que las Cruzadas habian fracasado en su intento de reconquistar Tierra Santa (Custodia Terrae Sanctae: Misioneros franciscanos al servicio de la Tierra Santa, 2014).

En el Concilio IV de Letrán en 1215 se consolida la Orden, participando activamente en ella Francisco. Al año siguiente del Concilio, muere el Papa Inocencio III y le sucede Honorio III, quien promovió en 1216 la indulgencia plenaria a favor de todo aquel que visitara la iglesia de Santa María de los Ángeles de Porciúncula. Obtuvo Francisco esa gracia del Papa para que la peregrinación se realizara una vez al año, pero bajo fuerte oposición, puesto que pocos lugares podian disfrutar de tan alto privilegio (Englebert, 1979, p. 152).

En 1217 se celebra el Primer Capítulo General de la Orden, dividiéndose en 12 Provincias -siendo una de ellas Tierra Santa-, lo cual revela el tremendo crecimiento de la misma. Entre el 15 de agosto y el 29 de septiembre de 1224, Francisco pasa la cuaresma de San Miguel en el Monte Alverna, distante unos $160 \mathrm{kms}$. al norte de Asís, junto a sus compañeros León, Ángelo, Illuminato, Rufino y Masseo. Dos años después (3/X/1226) recibe a la hermana muerte con una dolorosa enfermedad. Al cabo de otros dos años, el 16 de julio de 1228, el 
Papa Gregorio IX lo canoniza. Este Papa había sido amigo de Francisco y Protector de la Orden como Cardenal Hugolino de Segni. Este mismo Papa ordena iniciar la construcción de la Basílica de San Francisco de Asís, colocando la primera piedra, junto a fray Elías, al día siguiente de la canonización el 17 de julio de 1228 (Caiceo, 201,p. 17).

Este lugar se ha transformado en un importante centro de encuentros ecuménicos realizados por los últimos Papas: Juan Pablo II el 27 de octubre de 1986 y Benedicto XVI el 27 de octubre de 2011 (veinticinco años después); estos encuentros ecuménicos han servido para unirse en torno a un mismo Dios y orar por la Paz del Mundo. No hay que olvidar que Francisco fue un adelantado de su tiempo en cuanto a ecumenismo por su relación con el Islam.

\section{Surgimiento de dos Importantes Órdenes en el Siglo XIII.}

Es importante destacar que la Iglesia Católica sufría hacia finales del siglo XII y comienzos del XIII una seria crisis, motivada especialmente por el deseo de poder y riqueza que se había instalado desde el poder central. Por lo mismo, se requerían instituciones religiosas que, rescatando el evangelio, condujeran con el ejemplo y la predicación, una reconversión de la Iglesia a sus orígenes. El Papa Inocencio III, consciente de esa necesidad, aprobó la Orden Franciscana. Pero, paralelamente, en Castilla, España, nace Santo Domingo de Guzmán (1170-1221), quien vivirá en el mismo período de San Francisco. Este santo español también toma conciencia de la necesidad de una nueva orden religiosa que combata las herejías de su tiempo, especialmente la de los cátaros; por lo mismo, funda la Orden de Predicadores, conocida como la Orden Dominicana, apoyado por el Papa Inocencio III. Asiste al mismo Concilio de Letrán en 1215 en que está San Francisco; allí presenta su nueva Orden y el 22 de diciembre de 1216 el Papa Honorio III, a través de la Bula Religiosam Vital, le confirma la mencionada Orden.

Estas dos Órdenes, la franciscana y la dominicana, serán muy importantes en la restauración del catolicismo en sus fuentes evangélicas; ambas se conocen también como órdenes mendicantes. Su influencia no sólo será en los púlpitos y en la evangelización del pueblo, sino que también en el mundo universitario. Grandes teólogos y filósofos saldrán de sus filas y se ubicarán en los principales centros universitarios de la época, tales como Bolonia, Padua y Nápoles en Italia; Oxford y Cambridge en Inglaterra; Salamanca y Palencia en España y París en Francia. Alejandro de Hales, San Buenaventura, Roger Bacon, Juan Duns Escoto y Guillermo de Ockam sobresalen en la Orden Franciscana en torno a los siglos XIII y XIV. En el mismo período sobresalen los dominicos San Alberto Magno, Santo Tomás de Aquino, Maestro Eckart y San Vicente Ferrer (Caiceo, 2014, p. 20-21). A estos filósofos se los ubica dentro de la escolástica, el cual es un movimiento filosófico-teológico que se da entre los siglos XI y mediados del XV; en él se utiliza la filosofia grecolatina para comprender mejor la revelación cristiana; se producía una coordinación entre la fe y la razón, subordinándose ésta a la primera; por lo mismo, se señalaba que la filosofia era esclava de la teología (philosophia ancilla theologiae). Para Merino (1993: XXI), "los escolásticos eran profesionales de la fe, y por eso hacian teología. Como asimismo eran profesionales de la razón, y por eso hacian filosofia". Por lo mismo,

"la filosofia medieval se caracteriza por un fuerte sentimiento de trascendencia y por su vinculación a la fe que ofrece a la razón nueva luz y nuevos materiales de reflexión. Su esencial fisonomía espiritual está apoyada y forjada en el lema agustiniano de 'intellige ut credas, crede ut intelligas' (entiende para que puedas creer, cree para que puedas entender)" (Merino, 1993) 
La escolástica dejó atrás a la patrística, que fue la filosofia propia de los inicios del cristianismo; en efecto, con la extensión de la fe cristiana a partir del siglo II, surgen los denominados Padres de la Iglesia -de ahí el nombre de patrística-, quienes exponen y hacen entendible el cristianismo a los no cristianos, basado en la filosofia greco-romana imperante. En sintesis, la patrística se caracteriza por la defensa racional de la fe cristiana frente a los ataques del paganismo filosófico y religioso y la aceptación de las verdades filosóficas conciliables con la revelación cristiana; así, por ejemplo, San Agustín, considerado el último Padre de la Iglesia, cristianiza la filosofia platónica.

Ambas Órdenes religiosas nacen para restaurar el catolicismo en sus orígenes evangélicos; ambas instituciones se destacan por la predicación y el ejemplo de vida mendicante. Por lo tanto, podria pensarse que deberian haberse dedicado solamente a enseñarle al pueblo desde el púlpito, las escuelas y las parroquias. Sin embargo, sus miembros se dan cuenta de que el pensamiento teológico y filosófico relevante se está dando en las universidades; por lo mismo, también van allí y, tal como se verá, en los capítulos siguientes, importantes filósofos franciscanos -objeto de este texto- sobresaldrán en las principales universidades de la época, especialmente en Oxford y en París. También hay que tener presente que, como ambas Órdenes crecieron rápidamente, necesitaban lugares de alto nivel para formar a sus frailes.

Algo similar ocurrirá a partir del descubrimiento de América, puesto que ambas Órdenes Religiosas vendrán con los conquistadores y se destacarán por su defensa de los indígenas. Entre ellos, cabe mencionar a los franciscanos San Francisco Solano, el beato Sebastián de Aparicio y Fray Luis de Bolaños; y a los dominicos fray Antonio Montesinos y fray Bartolomé de las Casas. La filosofia también será preocupación de los franciscanos en esta parte del mundo; en el caso de Chile sobresalen dos importantes filósofos: Alonso Briceño en la colonia y Eduardo Rosales en el siglo pasado.

\section{Principales Centros Universitarios Franciscanos.}

Respecto a la incursión en los centros educacionales superiores de los franciscanos, ella comenzó en Bolonia, Italia, centro universitario muy importante en el siglo XIII. Allí aparecieron los Frailes Menores con Bernardo de Quintavalle, hacia 1211. San Francisco visitó en dos ocasiones el lugar (1220 y 1222), concediéndole en la segunda visita la calidad de Lector en Teología a San Antonio de Padua, quien se convirtió, de esta manera, en el primer profesor en Ciencia Sagrada de los franciscanos. Sin embargo, en la universidad no existía Facultad de Teología y, por lo tanto, los Frailes Menores estudiaban sólo en el Convento de Bolonia.

Para entender la filosofia franciscana hay que entender los presupuestos que la originaron. Por lo mismo,

"la filosofia franciscana hay que ubicarla y encuadrarla en el contexto socio-cultural y en la 'situación' en la que se forjó. Es hija de su tiempo y de sus circunstancias, que corresponden a la época del Medievo. Esta toma de conciencia histórica nos preparará para detectar y distinguir lo que es simple producto y efecto epocal de aquello que es válido y vigente de un sistema doctrinal. Es evidente que ciertas cosas que se escribieron entonces hoy no se dirian, como asimismo ciertas cosas que se silenciaron en aquel tiempo actualmente se proclamarian" (Merino, 1993) 
La incursión propiamente a la universidad, por parte de los franciscanos, comenzó en Oxford, Inglaterra en 1224 (Merino, 1993, p. 25). Por la práctica de la pobreza y el cultivo de la ciencia se ganaron rápidamente la simpatía de los estudiantes y especialmente del Canciller de la universidad, Roberto Grosseteste; esta autoridad -quien después será Obispo de Lincoln- creó cursos públicos en el Convento de los Frailes Menores en 1228, transformándose en el centro de la Facultad de Teología de Oxford; un rol importante desempeñó el Provincial de Inglaterra, fray Ángel de Pisa (Merino, 1993, p. 26). Diez años después, los propios franciscanos eran los profesores, destacándose Adán de Marsch y Tomás de York, discípulos de Grosseteste. De esta forma, se inició un movimiento teológicofilosófico de importancia, pues las enseñanzas se basaban en tratados árabes y traducciones recientes de Aristóteles y obras neoplatónicas, no usadas anteriormente. La situación es tal que, algunos autores como Dorothea Elizabeth Sharp (1930, p. 52), sostienen que Aristóteles llegó a Occidente no a través del dominico San Alberto Magno, como sostiene Mandonnet, sino que a través de la Escuela Franciscana de Oxford. Aquí sobresaldrán especialmente los dos ya mencionados -Adán y Tomás- y John Pecham, Ricardo de Middleton, Roger Bacon, Juan Duns Escoto y Guillermo de Ockam. Sin embargo, Merino (1993) afirma que es

"la corriente agustiniana la que domina todo el pensamiento franciscano. El hombre puede conocer el mundo, la naturaleza humana y todos los seres de la creación, pero todo ello serviría de muy poco si no se descubre en la naturaleza el 'vestigium Dei', la huella de Dios, y en sí mismo la 'imago Dei', imagen de Dios, si no percibe la acción divina en el alma".

Es necesario subrayar que Roberto Grosseteste es el gran impulsor de los filósofos franciscanos en Oxford y que, posteriormente, se trasladan a París, especialmente en la línea más científica de los mismos. Al respecto, se afirma:

"filósofo inglés, fuertemente influido por las ideas de Aristóteles, a quien leyó a través de comentaristas árabes y judíos. Se le considera el fundador de la tradición de pensamiento científico en el mundo intelectual británico medieval. Teorizó sistemáticamente sobre los diferentes aspectos de la ciencia experimental, distinguiendo entre los métodos inductivo, experimental y matemático" (Otero y Gibert, 2014, p. 122).

Franciscanos y Dominicos se instalaron en París, Francia; los primeros, en los suburbios, en el barrio de Saint-Denis en 1219; los segundos se habian instalado un año antes en pleno centro de la ciudad. Comenzó así una rivalidad de ambas Órdenes respecto a la influencia que podian tener en la Universidad de París; los primeros estaban en desventaja por la distancia en que tenían su convento; el Provincial de Francia era fray Gregorio de Nápoles. Sin embargo, esta situación cambió cuando en 1231 se dieron dos hechos relevantes: En primer lugar, el Papa Gregorio IX logró que los Frailes Menores pudieran instalarse en tierras de la abadía de Saint-Germain de Près, muy cerca del barrio universitario; en segundo lugar, uno de los más prestigiosos académicos tomó el hábito franciscano, fray Alejandro de Hales, quien había nacido en Inglaterra y había iniciado sus estudios en Oxford en donde conoce a Roberto Grosseteste. Alejandro organiza una Escuela que coloca en el primer plano de la universidad, transformando el Convento de los Franciscanos de París en el centro intelectual más importante de toda la Orden. Le sucede Juan de la Rupella, discípulo del mismo Alejandro. En la primera mitad del siglo XIII, Eudes Rigaud, más tarde Arzobispo de Ruán, Guillermo de Meliton, y finalmente San Buenaventura fueron las lumbreras de la cátedra de que los Franciscanos eran titulares en la Universidad de París (Merino, 1993, p. 24); aquí también estuvo Roger Bacon, aunque él estuvo más ligado 
a Oxford. A la Universidad de París arribará el dominico Santo Tomás de Aquino, teniendo cátedra paralela con San Buenaventura.

En sintesis, los filósofos franciscanos poseen un "horizonte mental que los distingue de otras escuelas" (Merino, 1993, p. XXVII). Lo fundamental radica en que "una cierta 'experiencia' personal y comunitaria está en la base del franciscanismo. Aquí la teoría y el sistema son el resultado de una vivencia y de una praxis condicionante del pensamiento" (Merino, 1993, p. XXVII).

En el próximo punto se expondrá el pensamiento de los principales filósofos franciscanos europeos -quienes estuvieron ligados a las dos principales escuelas ya mencionadas, Oxford (Rogerio Bacon, Beato Juan Duns Escoto y Guillermo de Ockam; surgieron en aquí, pero también se desarrollaron en París) y París (Alejandro de Hales y San Buenaventura).

\section{Pensamiento de los Principales Filósofos Franciscanos.}

Tal como se indicó en el punto anterior, hay dos hechos relevantes en los principales filósofos franciscanos: (i) Su participación activa en la gestación de la ciencia moderna y (ii) en una nueva forma de asumir la escolástica, combinando la filosofía aristotélica con la agustiniana.

\section{Participación en la gestación de la ciencia moderna.}

\section{- Roger Bacon}

Filósofo que nace en el suroeste de Inglaterra entre 1210; 1220 (Crowley, 1950, p. 21) y muere en Oxford en 1292 (Directorio Franciscano: Enciclopedia Franciscana), es el primer y más importante franciscano en este aspecto; se le conoce como el Doctor Mirabilis por la importancia de su aporte al pensamiento y la cultura. Finalizado sus estudios en París -que había iniciado en Oxford-, ingresa como profesor, conociendo al franciscano Alejandro de Hales y al dominico Alberto Magno, con quienes discrepa abiertamente y critica sus planteamientos. Su postura se basa en que no es aceptable seguir ciegamente los planteamientos de autoridades anteriores o teólogos que no incorporaran un conocimiento nuevo a sus reflexiones teológicas y menos las relacionaran con la filosofia y las ciencias; piensa que ello debe incorporarse al plan de estudios universitario. Es en este lugar que, durante su estada, escribe sobre gramática, física, lógica y metafísica (Merino, 1993, p. 130). Otorga una mayor preferencia a las ciencias -denominadas cuadrivio- que a las letras -conocidas como trivio-.

Regresa a Oxford en donde entre 1247 y 1250 toma contacto con Robert Grosseteste y su grupo, lo cual lo lleva a tener una visión cultural más amplia, estudiando la naturaleza y el desarrollo de la técnica. Estas incursiones más las que ya poseía de la cultura griega, a través de los árabes, lo condujo a señalar el método científico para acceder a la realidad, conocido como el empirismo, lo cual puso en jaque a la escolástica tradicional. Por lo mismo, se le conoce como científico, filósofo y teólogo. Estando aquí solicita libros bastante caros, pues debían copiarse a mano, y también diversos instrumentos. Ingresa a la Orden Franciscana, probablemente en el convento de Oxford, entre 1253 y 1257 (Merino, 1993, p. 125). 
Desde 1256 Bacon inicia un período dificil en su vida, pues sufre restricciones de sus superiores para escribir, ya que sus incursiones en la ciencia lo ponen en situación dificil para su tiempo. Además, se mantiene siempre fiel a sus ideas y ataca a quienes están en desacuerdo con sus posiciones, aunque fueran franciscanos; por ello, el nuevo director del trabajo intelectual de la Orden que asume ese año, Richard de Cornwall, y con el cual había tenido serias disputas, lo envía por 10 años a un Monasterio en Francia en donde su único medio de comunicación es la escritura. Hay personas que opinan que en realidad Bacon es encarcelado por Jerónimo de Ascoli, Ministro General de su Orden (Fraile, 1966, p. 764) en 1278 en Ancona -Italia- por difundir la Alquimia, algo prohibido en la época; sin embargo, hay discrepancias al respecto, pues si ello hubiera ocurrido, fue más bien por su posición radical a favor de la pobreza, de acuerdo al verdadero espíritu del fundador de los franciscanos (Directorio Franciscano, 2014)

Este destacado pensador franciscano vive intensamente las angustias y esperanzas de su tiempo. Por lo mismo, Merino lo describe como

"un intelectual apasionado y comprometido con su época, de la que hace una descripción apocalíptica. Vio, oyó, observó, comparó y criticó la sociedad, la Iglesia y la universidad, y propuso una alternativa cultural articulada y fundamentada en una teoría sinóptica de los diversos saberes. Los juicios severos y cáusticos que hace de casi toda la cultura y los maestros de su tiempo están motivados por el amor a la Iglesia y a la sociedad" (Merino, 2014, p. 525).

La práctica científica que adquiere Bacon en su formación lo lleva a tomar conciencia de los errores existentes en el debate académico de ese entonces. Ningún profesor aprende griego para leer directamente a Aristóteles o las Sagradas Escrituras; de alli que se nutren sólo de malas traducciones. Eso molesta fuertemente a Bacon; según él, la ciencia fisica no se desarrollaba por experimentos, sino que por argumentos basados en la tradición. De esta forma, Bacon se margina de la rutina escolástica y se transforma en un estudioso de las lenguas y la investigación experimental; por lo mismo, realiza varios experimentos, entre ellos, los de óptica (Caiceo, 2014, p. 33). Resulta muy importante subrayar que Roger Bacon se adelanta 300 años al planteamiento que hará Francis Bacon, también inglés, en su obra Novum Organum o Indicaciones Relativas a la Interpretación de la Naturaleza, publicada en 1620; aquí plantea la necesidad de poner en práctica el método empírico para desarrollar la ciencia; consagra definitivamente el método inductivo, es decir, partir de los hechos presentes o descubiertos en la realidad, para encontrar los principios o leyes. Este nuevo método, propio de la ciencia moderna contrasta con el método deductivo, propio de la filosofia clásica, especialmente utilizado por Aristóteles (Caiceo, 2013, p. 11). El propio Francis Bacon y el alemán Johannes Kepler, contemporáneo suyo, realizan, al igual que Roger Bacon experimentos sobre óptica. ¿En qué medida influyó Roger en estos científicos modernos? Posiblemente leyeron los textos de la Summa Scientiarum de Roger y tomaron conciencia de sus esfuerzos de tres siglos antes por instaurar la ciencia y ello los motivó más en el desarrollo de la misma. La preocupación científica de Roger Bacon se percibe claramente en esta frase: "la matemática es la puerta y la llave de toda ciencia" y en especial para la teología (Fraile, 1966, p. 762). "Sin la matemática no es posible entender la gramática y la lógica” Opus Maius IV (p. 99-100) (citado por Fraile, 1966, p. 766).

El mismo Bacon relata en su Opus Tertium el cambio cultural que le significa el encuentro con Grosseteste: 
"Durante veinte años, en los que me he aplicado especialmente al estudio de la sabiduria, he despreciado el modo común de pensar y he gastado más de 2.000 libras en adquirir obras secretas para hacer experiencia directa de las cosas más diversas, para aprender las lenguas, para procurarme instrumentos científicos, tablas astronómicas y otras cosas, como asimismo para lograr la amistad de los sabios, para instruir a los colaboradores en el conocimiento de las lenguas, en las figuras geométricas, en los cálculos aritméticos, en el uso de las tablas, de los instrumentos y de muchas cosas más" (Citado por Merino, 1993, p. 108).

Roger Bacon elabora un proyecto acerca de todo el saber humano que lo escribiría como Summa Scientiarum; lo anterior lo puso en conocimiento del Cardenal Guy le Gros de Folques, quien se interesó por ello y le solicitó que escribiese la obra completa. El pensador inglés estaba restringido por una regla de la orden franciscana que le prohibía publicar trabajos sin un permiso especial, por lo cual duda inicialmente de comenzar tamaño trabajo. Sin embargo, el Cardenal se convierte en el Papa Clemente IV e insistió con Bacon que ignorase tal prohibición y que escribiera el libro en secreto. De esta forma. Comienza escribiendo el primer volumen con el nombre de Opus Maius (1266/1268), el cual es un tratado sobre las ciencias de la época: Gramática, Lógica, Matemáticas, Física y Filosofia; se lo envía al Papa en 1267. Luego prosigue con el segundo volumen, al cual denomina Opus Minus (1267), también conocido como Opus Secundum, que contienen un resumen de los principales planteamientos de la obra anterior. Finalmente, en 1268 envía el tercer volumen con el nombre de Opus Tertium (1267/1268). El Papa muere y no alcanza a conocer la obra que él había instado a realizar (Merino 1993, p. 530). En toda la obra se percibe un análisis de los males del cristianismo, de la Iglesia y de la cultura y, al mismo tiempo, propone los remedios para llegar a una aetas nova (Merino, 1993, p. 531). En los volúmenes 2 y 3 arremete fuertemente contra algunos planteamientos de Alejandro de Hales; seguramente ello se funda en que Alejandro se basa en traducciones aristotélicas de los árabes y en que acepta la deducción como método exclusivo para desarrollar el saber. La misma crítica al método aristotélico harán tres siglos después los padres de la ciencia moderna, especialmente Francis Bacon y Johannes Kepler, mencionados anteriormente. Estas críticas significan que Roger Bacon sea recibido en París con aplausos, como si fuera un personaje de la talla de Aristóteles, Averroes o Avicena (Caiceo, 2014, p. 34).

En 1292, año de su muerte, se publica su última obra: Compendium studii theologiae, obra interesante porque en ella vincula sus primeras investigaciones sobre lógica y teoría de los signos con su idea unitaria del saber filosófico-teológico.

Su posición filosófica se acerca más a la de Avicena; él mismo señala que "Avicena fue mayor que Averroes y el principal intérprete de Aristóteles" Opus Tertium, (citado por Fraile, 1966, p. 767).

Para Bacon hay tres fuentes de conocimiento: la autoridad, la razón y la experiencia, siendo la tercera la fundamental, ya que la autoridad por sí misma no basta y la razón requiere de la experiencia. Existe una experiencia externa, la cual proviene de los sentidos, y una experiencia interna, derivadas de las inspiraciones divinas; es decir, el iluminismo está presente en este pensador (Fraile, 1966, p. 769). ¿Será esto último influencia platónica o agustiniana?

En opinión de Étienne Gilson, gran estudioso de la Filosofia de la Edad Media, lo sorprendente de Roger Bacon, más que su doctrina es 
"ese espíritu que lo anima, que le confiere su interés y le asegura un puesto permanente en la historia de las ideas. Si se piensa en las condiciones miserables en las que R. Bacon vivió, en las incontables dificultades, de las que él mismo se lamentó sin cesar, porque le impidieron escribir, uno queda atónito ante ese genio desdichado que solo en el siglo XIII, y tal vez hasta Augusto Comte, soñó una sintesis total del saber científico, filosófico y religioso para conseguir la unidad de la sociedad universal de todo el género humano" (Gilson, 1947, p. 482).

Otero y Gibert (2014, p. 28) sostienen sobre Roger Bacon:

"Filósofo inglés, una curiosa mezcla de persona interesada en la alquimia y la magia y, al mismo tiempo, en las matemáticas y los métodos experimentales. Defendió la relevancia de estos últimos para el mejoramiento del conocimiento humano, al que concibió como un medio para la instauración de una república cristiana".

\section{- Guillermo de Ockham.}

Según algunas fuentes es natural de Ockham, al sur de Londres; nace entre 1280 y 1288 , aunque se señala explícitamente el año 1285 o el 1295 en Fraile (1996, p. 780); muere en Munich en 1349. Por su trayectoria existencial se le conoce como el Doctor Invincibilis, el Venerabilis Inceptor o el Doctor Singular (López, 2012: 265). Ingresa muy joven a la Orden Franciscana y estudia, primero en el Convento de Londres y, luego en Oxford, obteniendo el grado de Bachiller, según algunos o el de Maestro, según otros entre los años 1616 a 1620; ejerce como lector de las Sentencias de Pedro Lombardo en Oxford; enseña en Paris hasta 1323, año en que es acusado de herejía y es citado a la Corte Pontificia en Aviñón; otros, afirman que solo estudia en Oxford y París y se dedica a escribir sus textos más polémicos por los cuales es juzgado y por los cuales se le recuerda en el plano teológico y filosófico; sin embargo, todos coinciden en que fue discipulo del Beato Juan Duns Escoto.

El Canciller de la Universidad de Oxford, Juan Luterell, realiza las acusaciones en contra de Fray Guillermo; el Papa Juan XXII nombra una Comisión de seis teólogos para examinar los escritos del fraile franciscano: el propio acusador, dos Obispos de la Orden de Ermitaños de San Agustín, dos dominicos y Durando de Saint Pourçain, quienes entre 1324 y 1328 examinan las 51 proposiciones extractadas de sus comentarios a las Sentencias de Pedro Lombardo; Ockham mantiene su postura y finalmente el Papa no lo condena sino que solo lo censura; para reconciliarse escribe su obra De Sacramento Altaris con elementos de ortodoxia (Fraile, 1996, p. 785). Existen otros desencuentros entre los franciscanos denominados conventuales y los espirituales acerca de la pobreza, por una parte, y entre el Emperador Luis IV y el Papa Juan XXII, por otra. Frente a estos acontecimientos, Guillermo de Ockham, molesto por su retención en Aviñón, apoya la posición de su Ministro Superior y de Luis IV. Junto a su Superior y a Bonagrazia de Bérgamo, Francisco de Ascoli y Enrique Thalheim redactan en mayo de 1328 un documento en contra del Papa; a continuación huyen, primero a Italia y luego a Alemania (Baviera). Esta situación significa la excomunión, en 1327, del Superior Franciscano y sus tres acompañantes. El centro de la controversia franciscana y el papado es la discusión sobre la verdadera pobreza apostólica. Ockham, por su parte, lo que busca es limitar el poder extralimitado del Papado y circunscribirlo a la realidad evangélica (López, 2012, p. 270). Muerto el Papa, la lucha prosigue en contra de Benedicto XII; sin embargo los rebeldes van muriendo y solo queda vivo Fray Guillermo, quien remite el sello de la Orden -dejado a él en custodia por Fray Miguel- al Capítulo General de Verona en 1348, para que se entregara al nuevo General, Fray Guillermo Farinier, gesto que es tomado como una cesación de la lucha y, en cierta forma, sumisión a 
la nueva autoridad de su Orden (Fraile, 1996, p. 786). Fue rehabilitado póstumamente por la Iglesia oficial en 1359.

Los escritos anteriores a su permanencia en Aviñón son de corte teológico-filosófico; en cambio, los posteriores, son de orden filosófico-político, por su insistencia en la separación de poderes.

Las obras filosóficas y teológicas de Ockham han sido publicadas en una edición crítica latina en 17 tomos correspondientes a dos series: Obras teológicas (10 tomos) y obras filosóficas (7 tomos) por profesores del Franciscan Institute, vinculado a la Universidad de San Buenaventura de Nueva York entre 1967 y 1988 con el título genérico: Opera Philosophica et Theologica ad fidem codicum manuscriptorum editado por el Instituto Franciscano de la Universidad de San Buenaventura de Nueva York. La mayoría de sus obras polémicas han sido publicadas por un equipo dirigido por Offer entre 1956 y 1997. Este trabajo se ha desarrollado fundamentalmente en Inglaterra (Caiceo, 2014, p. 56).

El pensamiento de Guillermo de Ockham supone un giro del pensamiento escolástico: es casi una disolución del mismo; es considerado el último gran filósofo de la Edad Media y el más grande nominalista de la historia; junto a su hermano de la Orden, Beato Juan Duns Escoto, son considerados "los dos metafisicos más profundos que jamás vivieron" (Pierce, 1869 en Caiceo, (2014, p 56) , los cuales ponen fin a una etapa de la filosofia cristiana, encabezada por las síntesis agustiniana de San Buenaventura y la aristotélica de Santo Tomás e inician una nueva: separación entre la razón y la fe, entre la filosofia, que gana independencia, y la teologia; son considerados filósofos relevantes del medievo, junto a Agustín de Hipona, Alberto Magno, Tomás de Aquino, Buenaventura de Fidanza, Nicolás de Cusa y Giordano Bruno (Gilson, 1947, p. 128) ; (Fraile, 1996, p. 788). Ockham es mucho más radical y para él no se puede demostrar racionalmente ni la existencia de Dios ni los atributos divinos; estos problemas quedan para el ámbito de la revelación, propio de la Teología.

Fray Guillermo, principal nominalista de la historia, es considerado por algunos como el padre de la epistemología y de la filosofia moderna, en consideración a su estricta argumentación de que solo los individuos existen, más que los universales -los cuales son esencias o formas supra individuales-, y que los universales son producto de la abstracción de individuos por parte de la mente humana y no tienen existencia fuera de ella. Ockham es considerado por algunos especialistas como un defensor del conceptualismo más que del nominalismo, ya que mientras los nominalistas sostienen que los universales son meros nombres, es decir, palabras más que realidades existentes, los conceptualistas sostienen que son conceptos mentales, es decir, los nombres son nombres de conceptos, que sí existen, aunque sólo en la mente (Fraile, 1966, p. 790).

La confianza puesta por Guillermo de Ockham en la experiencia directa (conocimiento intuitivo) y la negación de la existencia de los universales suponen un precedente de lo que más tarde va a constituir el denominado empirismo moderno inglés. Su postura es continuación de la corriente iniciada en Oxford por Roberto Grosseteste y seguida por Roger Bacon. El empirismo científico lo recoge e inicia a fines del siglo XVI el también inglés Francis Bacon y en el plano filosófico lo fundamenta en el siglo siguiente el también inglés John Locke (Rábade, 1996, p. 150). Esta posición centrada en el conocimiento de la realidad por la intuición, valorando la experiencia, hace que por ese camino filosófico, Ockham "se convierte en el precursor de la investigación naturalista propia del Renacimiento" (López, 2012, p. 265). 
En relación a su posición sobre el conocimiento se señala:

"Defendió la inducción sobre la base de sostener el conocimiento intuitivo -percepción de cosas individuales a través de los sentidos- y de respaldar el principio de economía. Pero en franca oposición a las de Grosseteste y Duns Escoto, y en general a la influencia aristotélica, mantuvo una actitud escéptica frente a la posibilidad de conocer las conexiones causales particulares. Sostuvo que las relaciones entre las cosas no tenían realidad objetiva, sino que eran conceptos formados por la mente. En consecuencia, las explicaciones de la filosofia natural no podían ser necesarias sino probables. Debió comparecer ante una Comisión Papal por sus enseñanzas, algunas consideradas heréticas" (Otero y Gibert, 2014, p. 183-184).

En el ámbito de la lógica, Ockham trabaja en dirección a lo que más tarde se llamaria Leyes de De Morgan y lógica ternaria, es decir, un sistema lógico con tres valores de verdad, concepto que sería retomado en la lógica matemática de los siglos XIX y XX (López, 2012, p. 270).

Por su defensa de la libertad de conciencia en su postura frente al Papado, se afirma que Lutero lo toma como su maestro (López, 2012, p. 265). Por otra parte, la posición de Fray Guillermo se liga con el laicismo, es decir, el rol que deben tener los laicos en la Iglesia, situación que se consolida definitivamente sólo en el Concilio Vaticano II (1962-1965). Ockham plantea que un gobernante aunque sea coronado por una autoridad eclesiástica (Papa u Obispo), éste no tiene derecho a deponerlo; declara que los clérigos deben ser fieles con los laicos y el derecho de ellos de resistir a la hostilidad clerical (Ockham, 1992: 189 y ss.).

\section{Los Franciscanos y una nueva forma de asumir la escolástica.}

\section{- Alejandro de Hales.}

Nace en la actual Owen (ex Hales) en Inglaterra, probablemente en 1185 o 1186; muere en París el 21 de agosto de 1245 (AA, 1907: 235), víctima de una grave enfermedad, después de haber participado en el Concilio de Lyon realizado ese mismo año (Merino, 1993: 590). En 1231 ingresa a la Orden Franciscana en París, compatibilizando su rol de fraile, profesor de la Facultad y del curso en el Convento.

Sus principales obras son tres: La principal, encomendada por Inocencio IV fue la Summa Theologiae o Summa Universae Theologiae; quedó sin finalizar y la completaron alumnos de Alejandro después de su muerte. De ella existen varias publicaciones: Venecia, 1475 y 1576; Nuremberg, 1481 y 1502; Pavia, 1481; Colonia, 1622. Sus otras dos obras son: Glossa in quatuor libros Sententiarum Petri Lombardi y las Quaestiones disputatae antequam esset frater. La primera obra la inició a pedido de Inocencio IV -tal como se indicó precedentemente- y aprobada finalmente por Alejandro IV, después de ser sometida a juicio de un grupo de setenta teólogos, quienes la encontraron excelente y la juzgaron como un texto modelo para todos los maestros de teología. Por este escrito se le conoce como el Doctor Irrefragabilis (Merino, 1993, p. 555).

Su pensamiento fundamental se encuentra en su primera obra y su importancia para la historia de la teología y de la filosofia radica en haber sido el primero en intentar una exposición sistemática de la doctrina católica, después de que las obras metafísicas y fisicas de Aristóteles se habían dado a conocer a los maestros (AA, 1907, p. 248). Para desarrollar 
su obra utiliza el método propio de la escolástica, denominado disputatio o disputa: Cada punto que desarrolla lo denomina artículo, frente al cual coloca las objeciones existentes; luego indica las tesis con pruebas bíblicas, de la patrística y juiciosas con antecedentes de poetas y filósofos griegos, latinos y musulmanes, y teólogos posteriores; finaliza con la resolución, entregando respuesta a las objeciones indicadas primeramente. La Summa está dividida en cuatro partes: la primera trata de Dios y sus atributos; la segunda, de las criaturas y el pecado; la tercera de Cristo, la salvación y la expiación; la cuarta, de los sacramentos (AA., 1907, p. 250).

Según The Catholic Encyclopedia (1907, p. 253), Alejandro de Hales cita en cada Quaestio (Cuestión o Pregunta) a Aristóteles; también a los comentadores árabes del mismo, especialmente a Avicena, preparando, de esta forma, el camino para que San Alberto, Santo Tomás, San Buenaventura y Duns Escoto conocieran bien al estagirita y fuera llamado por ellos como el Filósofo. Sin embargo, existen otros comentarios en torno a que su mayor inspiración fue la filosofia agustiniana (Merino, 1993, p. 557). Independientemente de esta discusión, lo importante es que Alejandro de Hales fue uno de los principales exponentes de la escolástica medieval; que con San Buenaventura serán los mayores representantes de la Escuela de París de la Orden Franciscana y de la universidad del mismo nombre durante el siglo XIII; y que el mayor exponente dominico de ese siglo y gran defensor de Aristóteles -por algo se le conoce como el cristianizador del Filósofo-, Santo Tomás de Aquino, tuvo como referente para su Summa Theologiae la Summa Universae Theologiae del "Doctor Irrefragabilis"; más aún, según Juan Gerson (1987, p. 12), cuando alguien le preguntó a Santo Tomás cuál era la mejor manera de estudiar teología, replicó que era la de seguir a un Maestro, refiriéndose a Alejandro de Hales.

En cuanto a la filosofia de Alejandro, su temática es amplia y abarca temas sobre la contingencia del mundo, la teoría hilemórfica, la teoría del conocimiento, la antropología y sobre la existencia y esencia de Dios.

En relación a la contingencia del mundo se aparta de la postura aristotélica que afirmaba la eternidad del mismo; en ello sigue a los planteamientos de Grosseteste, académico de Oxford. Hales afirma que la eternidad es una categoria divina y una propiedad propia de Dios. "Por lo tanto, ningún ser, fuera de Él, puede ser eterno. Ni el mundo en cuanto tal ni las cosas particulares pueden gozar de esa categoría eterna” (Merino, 1993, p. 14).

Respecto a la teoría hilemórfica asume y defiende el planteamiento de Aristóteles. Esta teoría afirma que la esencia de todo ser consta de materia y forma. La materia es de lo que está constituida la esencia de un ser y la forma es cómo se determina tal materia. Una silla, por ejemplo consta de madera y fierro, pero quien determina que esa madera y ese fierro sea silla es su forma; en el caso del hombre, la materia es su cuerpo y la forma es su espíritu (Caiceo, 1992, p. 25). A su vez, esta composición o estructura del ser se complementa con otra, la de acto y potencia; por la primera un ser es algo en acto (los estudiantes de este colegio son alumnos e hijos) y algo más en potencia (el mismo alumno en potencia es padre, madre, profesional) (Caiceo, 1992, p. 26). En el fondo todos los seres constan de partes y ellas tienen sentido por el todo.

Para comprender la teoría del conocimiento, Hales aplica las estructuras del ser ya señaladas, materia y forma y acto y potencia. Por lo mismo, distingue en el espíritu humano (en su forma) una actividad y una pasividad; el entendimiento agente es lo primero; y el entendimiento posible es lo segundo. Ambas partes son dos diferencias en el alma racional (la humana) para llevar a cabo el proceso del conocimiento. Textualmente, Hales señala: 
"El entendimiento agente y el entendimiento posible son dos diferencias en el alma racional; de lo cual la una, es decir, el entendimiento agente, está de la parte de la forma del alma misma, en cuanto espíritu; y la otra, es decir, el posible, está de parte de la materia, con la que es ente en potencia respecto a los cognoscibles que se hacen en esa parte" (Hales, 1924-1948, p. 452).

Respecto al problema de los Universales, tan común en la Escolástica,

"Alejandro asume la posición de un metafísico y de un psicólogo, alcanzando así una conclusión, a la cual sus precursores del siglo XII nunca hubieran podido alcanzar, al argumentar la pregunta únicamente desde el punto de vista dialéctico; él enseñó que los Universales existieron 'ante rem' (antes de que la cosa o ser exista), en la mente de Dios, y también 'in re' (en la cosa o ser mismo), como formas o esencias del intelecto activo abstracto. Esta es la conclusión del Realismo Moderado” (AA, 1907, p. 260).

Su planteamiento sobre el hombre está basado también sobre la teoría hilemórfica aristotélica, afirmando que es un compuesto de cuerpo (materia) y alma racional (forma); sin embargo, la interpretación y explicación de esta unión de cuerpo y alma racional la realiza en perspectiva agustiniana; textualmente señala:

"El alma racional se une a su cuerpo como el motor movible y como la perfección formal a la realidad que perfecciona" (Hales, 1924-1948) ... "El alma tiene con el cuerpo la misma relación que el marinero tiene con la nave. Pero el marinero, según la substancia, se distingue de la nave, pues mueve la nave y (ella) sólo accidentalmente se mueve; por lo tanto, el alma es substancia distinta del cuerpo"

( p. 420).

El alma racional posee tres facultades que son la intelectiva, la sensitiva y la vegetativa, a juicio de Alejandro, prosiguiendo la postura agustiniana al respecto. Prueba, a su vez, la inmortalidad de la misma con diversos argumentos; uno de ellos y el primero está basado en el deseo de felicidad que tiene todo espíritu: Señala: Dado que el alma, por su propia naturaleza, aspira a la felicidad, en su misma naturaleza será inmortal. Este argumento está tomado de la causa final" (Hales, 1960, p. 558).

Uno de los aspectos fundamentales del hombre es su libre arbitrio. Para Alejandro, el arbitrio está identificado con la razón y lo libre con la voluntad. El hombre por la razón tiende a la verdad y por la voluntad tiende al bien, pero en la medida que se mencione el libre arbitrio, toca a ambos aspectos a la vez (Merino, 1993, p. 360).

Para este pensador franciscano, el hombre es imagen de Dios, como indica la Biblia en el Génesis, no sólo por su alma racional, sino que también por su composición de cuerpo y alma, de acuerdo al modelo de la encarnación en la que Cristo asumió la naturaleza humana; por lo mismo, el cuerpo participa de la prerrogativa de imagen de Dios en cuanto está unido al alma. De esta forma, este autor está contra las tesis difundidas en el siglo XII, en el sentido que sólo el espíritu es imagen de Dios; ello no es así, según Alejandro, porque el cuerpo también es manifestación del amor de Dios (Merino, 199, p. 362).

Sin embargo, su preocupación principal se centra en la Teodicea. Sus planteamientos teológicos son muy similares a los de San Buenaventura y Santo Tomás de Aquino. En efecto, su tesis inicial, al preguntarse si Dios es cognoscible, sostiene que la mente humana puede saber quién es Él, pero no comprender cómo es Él. Siguiendo su método parecido a la disputa medieval, al enumerar las pruebas de la existencia de Dios, señala el argumento 
de San Agustín de la necesidad de una verdad absoluta; el argumento ontológico de San Anselmo; el argumento de Hugo de San Víctor del conocimiento y el argumento aristotélico de la causalidad . Planteó que Dios es la causa eficiente "y la causa final de todas las cosas, que Él es el creador y el Preservador de todas las cosas, que Él es la pura Realidad (Actus Purus)" (AA, 1907, p. 263); concluye en forma muy optimista que todos los hombres, buenos o malos, pueden llegar a conocer la existencia de Dios.

\section{- San Buenaventura.}

El nombre civil de este importante filósofo franciscano es Juan de Fidanza. Nace en Bagnoreggio, una pequeña ciudad cerca de Viterbo en Italia -zona de la Toscana-, según algunos en 1218 (Merino, 1993, p. 401) y otros en 1221 (Meseguer, 1959, p. 122). Fallece mientras estaba como Padre Conciliar en su calidad de Superior de la Orden Franciscana durante el Segundo Concilio Ecuménico de Lyon el 15 de julio de 1274. En 1243 ingresa a la Orden Franciscana, motivado por la sencillez evangélica de la misma y por la preocupación por el saber que la institución demuestra en sus centros universitarios. Sus estudios de Teología los finaliza en la Universidad de París, principal centro académico de la época; sus maestros más importantes son Fray Alejandro de Hales -a quien admira y lo llama "maestro y padre de feliz memoria" (Merino, 1993, p. 30) y el dominico Alberto Magno; uno de sus compañeros y, pronto colegas, es Tomás de Aquino.

El 2 de febrero de 1257 es elegido por la Orden reunida en Capítulo en Roma como el séptimo Ministro General, sucesor de Francisco de Asís. La institución religiosa estaba tensionada entre los severos inflexibles, denominados los espirituales, y los que solicitaban que las reglas se mitigaran. Gran trabajo le toca, por lo tanto al nuevo Ministro General: Adapta las reglas en el Capítulo de 1260 que se lleva a cabo en Narbona. Se le conoce como el Seráfico Doctor.

Aunque dedicado exclusivamente a su vida académica -combinada, por cierto, con sus deberes religiosos-, debido a su cargo, no está más de 10 años, su producción filosóficoteológica es fecunda y, además, profunda. Posee muchas obras: Según Merino \& Martínez (2004, p. 255) existen siete publicaciones sobre las Obras Completas del Doctor Seráfico, comenzando por la primera en Roma en 7 volúmenes entre 1588 y 1599; la última es la de la Biblioteca de Autores Cristianos -B.A.C.- en Madrid en 6 volúmenes desde 1945 en adelante.

El pensamiento de San Buenaventura surge de la síntesis entre escuchar, reflexionar y transmitir; usa la razón, pero también el corazón; es un místico que con la filosofía pretende que el hombre se acerque a Dios, lo descubra. Para transmitir ese mensaje, que ha meditado, reflexionado e interiorizado, busca el lenguaje retórico más adecuado para convencer, para poder entregar su sabiduría. En este sentido, se inspira más en San Agustín que en Aristóteles, pues la filosofía y la razón son los elementos que ayudan al alma humana para conducirla hacia Dios. Textualmente señala: "Algunos (los Predicadores) consideran de manera principal la especulación 'cuyo nombre también aceptaron' y después la unión (del alma con Dios). Y otros (los Menores) consideran de manera principal la unión y después la especulación” (San Buenaventura, 1251 en Fraile, 1996, p. 724). No busca en la filosofia y las ciencias un aspecto puramente intelectual o un fin en sí mismo, "sino que son un medio para elevar el alma a la contemplación, a la unión y al amor de Dios" (Fraile, 1996, p. 724). También encuentra aspectos propios de la filosofia platónica y aristotélica que los une en una sintesis con San Agustín; indica: "Asi también, se ve que entre los filósofos se da lo que Platón denomina discurso de sabiduría y Aristóteles verdadero discurso de la 
ciencia... Pero de ambos, según San Agustín, brota el discurso de la sabiduría y de la ciencia, iluminado por el Espiritu Santo" (San Buenaventura, Sermones selecti, (citado por Fraile, 1996, p. 724/725).

Para Buenaventura la Filosofia busca descubrir, aclarar y exponer la verdad. La define textualmente: "La ciencia filosófica no es otra cosa que el conocimiento cierto de la verdad en cuanto objeto de investigación" (San Buenaventura, 1268: col. 4, n. 5). Respecto al objeto de la Filosofia, indica: "La filosofia trata de las cosas como existen en la naturaleza o en el alma por el conocimiento dado naturalmente o también adquirido" (San Buenaventura, 1993) Sin embargo, lo más relevante es señalar el objeto formal de la Filosofia:

"La tercera luz, que ilumina en la investigación de las verdades inteligibles, es la luz del conocimiento filosófico, que se llama interior porque inquiere las causas íntimas y ocultas de las cosas, lo que realiza a través de los primeros principios de las ciencias y de la verdad natural impresos en el hombre por la misma naturaleza" (San Buenaventura, 1993).

\section{- Beato Juan Duns Escoto.}

Nace entre el 1265 o 1566 (Merino, 2007, p. 60) en Duns, pequeña ciudad escocesa situada en el Condado de Berwick, al sureste de Escocia (Directorio Franciscano, 2014) . Al cumplir 15 años (1280) ingresa al noviciado de la orden franciscana, gracias a la intervención de su tío franciscano Elias Duns, en el Convento de Dumfries, en donde este pariente es el Custodio de Escocia. Sus estudios superiores los realiza en Oxford, Cambridge y París (Fraile, 1966, p. 805). Se le conoce como el Doctor Sutil.

Por la reputación como maestro, Escoto recibe el título de Doctor en 1305. Enseña en París como maestro regente entre 1306 y 1307. A finales de 1307 es trasladado a Colonia como Lector principales, ciudad en la que muere muy joven el 8 de noviembre de 1308 (Merino, 2007, p. 75). Está enterrado en la Iglesia de los Hermanos Menores Conventuales de esa ciudad alemana; en su sepultura se puede leer el siguiente epitafio en latín: "Scotia me genuit / Anglia me suscepit / Gallia me docuit / Colonia me tenet)” Merino, 2007)

Escoto impulsa el deseado diálogo con los anglicanos, en base a las antiguas tradiciones comunes. En ese sentido, Escoto resulta una figura muy significativa: por una parte, fue siempre fiel al Magisterio eclesiástico; por otra, él es también un personaje ilustre de la Gran Bretaña. Además, su doctrina fue materia común, durante tres siglos, en las escuelas de aquel país (Carbajo, 2008, p. 78).

El Doctor Sutil vive una época muy compleja en cuanto a las corrientes filosóficas imperantes; circulan los escritos aristotélicos traducidos por los árabes, las famosas Sentencias de Pedro Lombardo, la posición de Santo Tomás de Aquino, la de San Buenaventura y él busca ser fiel a la posición que juzgue más segura. Por lo mismo, explica tres veces el libro de las Sententias de Pedro Lombardo; de ahí que haya tres Comentarios a las Sententias. La primera versión la hizo en Oxford, cuya redacción lleva el nombre de Lectura. El segundo comentario lo hizo en París, del que sus alumnos hicieron la redacción, llamado Reportata parisiensia. El último comentario, que tiene en cuenta los anteriores, se llama Ordinatio u Opus Oxoniense, que comenzó en Oxford y terminó en París. Esta es su obra maestra (Merino, 2007, p. 89). 
Escoto está empeñado en construir un sistema filosófico coherente con la tradición agustiniana de los franciscanos; sin embargo, abandona la teoría agustiniana de la iluminación, influido por Aristóteles, quien sostiene que el conocimiento de las verdades y esencias universales se logra por la abstracción. Sin embargo, se aleja de Santo Tomás, seguidor de Aristóteles, en lo concerniente al conocimiento de las realidades singulares: El entendimiento, para él, conoce directamente las realidades individuales por medio de una intuición inmediata confusa. De esta manera, el entendimiento capta en forma abstracta lo universal y directa e intuitivamente lo individual (Caiceo, 2013, p.14).

En cuanto a su importancia en la historia del pensamiento y de la filosofia franciscana, basta citar a Coreth (2006, p. 139) para tomar conciencia de aquello: "Juan Duns Escoto es un pensador de especial agudeza como critico, pero también de ideas independientes". Por la precisión de su lenguaje y fineza del mismo cuesta seguir el hilo de su argumentación; sus criticas van dirigidas fundamentalmente a Santo Tomás de Aquino, Egidio Romano, Godofredo de Fontaines, Enrique de Gante e incluso contra el fraile franciscano Roger Bacon.

\section{Conclusiones.}

Al finalizar este artículo, el autor piensa que se han cumplido los objetivos planteados en la Introducción, al subrayar el origen de la Orden Franciscana en el siglo XIII, la cual desde sus inicios se centró en tres principales Escuelas Filosóficas (Bolonia, Oxford y París), sobresaliendo en la última con los cinco destacados pensadores estudiados, los cuales se caracterizaron por iniciar en el ámbito universitario el método inductivo, base de la ciencia moderna (Bacon y Ockham) y por introducir en la escolástica una nueva posición: conciliar el aristotelismo con el agustinismo (Alejandro de Hales, San Buenaventura y Beato Juan Duns Escoto). Cabe resaltar que estos dos puntos señalados son muy relevantes, no sólo desde el punto de vista de la filosofia franciscana, sino que fundamentalmente desde la perspectiva del desarrollo del pensamiento filosófico -unificando las dos principales posturas de la escolástica medieval- y originando los prolegómenos de la filosofia y de la ciencia modernas. Resulta especialmente significativo que de los cinco destacados filósofos estudiados, cuatro de ellos emerjan de los territorios del actual Reino Unido y uno de la actual Italia; sin embargo, todos ellos se destacarán en París -Francia-, lugar que sobresaldrá en la cultura de la Baja Edad Media y que se prolongará con el resurgimiento de la filosofia con René Descartes en la época Moderna.

En la investigación inicial, influenciado por la fuerte formación aristotélico-tomista del autor de la misma y por la sencillez y humildad de los miembros de la Orden Franciscana, la hipótesis inicial apuntaba a una presencia discreta de los franciscanos en el desarrollo filosófico; sin embargo, los antecedentes encontrados contradicen tal planteamiento y se puede concluir a la luz de los puntos señalados en el párrafo anterior, que la Orden Franciscana se destacó desde sus orígenes por volver a la vivencia del Evangelio de Jesucristo, a conciliar el pensamiento agustiniano y tomista, presentes en la Edad Media, y a entregar las bases de la ciencia moderna. Es decir, se logró mucho más de lo esperado: fuerte presencia e influencia filosófica, complementada por la vivencia evangélica y por los prolegómenos de la ciencia.

Más aún, al analizar las diversas obras de los diferentes filósofos estudiados, se abre como perspectiva pedagógica, el estudio en sus textos de las diversas disciplinas filosóficas abordadas en los mismos, a saber, lógica, gnoseología, epistemología, metafísica, ética y teodicea. Además, la investigación puede continuar descubriendo filósofos en tierras americanas, especialmente en nuestro subcontinente y durante el período colonial. 


\section{Referencias bibliográficas.}

Sharp, D. E. (1930). Franciscan Philosophy at Oxford in the Thirteenth Century. Farnborough (Hants.)Gregg P.

AA. (1907). The Catholic Encyclopedia (Vol. I). New York: Robert Appleton Company.

Caiceo, J. (1992). En Torno al Problema del Ser. Santiago de Chile: Ediciones del Instituto Profesional de Estudios Superiores Blas Cañas.

Caiceo, J. (2013). "Crisis de la Epistemología de las Ciencias Sociales y la Educación Comparada". XV Congreso mundial de educación comparada. Buenos Aires: Universidad de Buenos Aires - Consejo Mundial de Sociedad de Educación Comparada.

Caiceo, J. (2014). Filosofia Franciscana: Principales Autores en sus Textos. Santiago de Chile: Ediciones Colegio Santa Isabel de Hungría.

Carbajo, M. (2008). "Actualidad de Duns Escoto en la Sociedad de la Información”. En M. Carbajo, Giovanni Duns Scoto Studi e ricerche nel VII Centenario della sua morte II. Roma: Antonianum.

Coreth, E. (2006). Dios en la Historia del Pensamiento Filosófico. Salamanca: Sígueme.

Crowley, T. O. (1950). Roger Bacon: The Problem of the Soul in His Philosophical Commentaries. Louvain-Dublin.

Custodia Terrae Sanctae: Misioneros franciscanos al servicio de la Tierra Santa. (2014). Periodo de fundación. Obtenido de es.custodia.org: http://es.custodia.org/default. asp?id=495.

Directorio Franciscano. (2013). San Francisco de Asis 1182 - 1226. Obtenido de www. franciscanos.org: http://www.franciscanos.org/sfa/menud.html

Directorio Franciscano. (2014). Enciclopedia Franciscana. Obtenido de www.franciscanos. org: http://www.franciscanos.org/enciclopedia/tau.htm

Directorio Franciscano. (2014). Santoral Franciscano, Beato Juan Duns Escoto. Obtenido de www.franciscanos.org: http://www.franciscanos.org/santoral/menud.html

Englebert, O. (1979). St. Francis of Assisi, A Biography. Estados Unidos de América: Servant Books.

Fraile, G. (1966). Historia de la Filosofía (Vol. III). Madrid: Biblioteca de Autores Cristianos -BAC.

Gerson, J. (1987). Opera Omnia. Hildesheim: Olms.

Gilson, É. (1947). La philosophie au Moyen Äge. Paris: Payo. 
Hales, A. (1924-1948). Summa Theologica. Quarachi.

Hales, A. (1960). Quaestiones Disputatae. Quarachi.

Joergensen , J. (1913). San Francisco de Asís. Santiago de Chile.

López, N. (2012). "Guillermo de Ockham y el Nacimiento del Laicismo Moderno". Anales de la Cátedra Francisco Suárez (46), 263-280.

Merino, J. A. (1993). Historia de la Filosofia Franciscana. Madrid: Biblioteca de Autores Cristianos- B.A.C.

Merino, J. A. (2007). Juan Duns Escoto: Introducción a su pensamiento filosófico-teológico. Madrid: Biblioteca de Autores Cristianos -BAC.

Merino, J. A., \& Martínez, F. (2004). Manual de Filosofia Franciscana. Madrid:: Biblioteca de Autores Cristianos -B.A.C.

Meseguer, J. O. (15 de Julio de 1959). San Buenaventura (1218-1274). Obtenido de www. franciscanos.org: http://www.franciscanos.org/bac/buenaventura.html

Ockham, G. (1992). Ocho cuestiones sobre la potestad del papa. Madrid: Centro de Estudios Constrituciones, Obra Política I.

Otero, E., \& Gibert, J. (2014). Diccionario de Epistemología. Santiago de Chile: Ediciones Universidad Central.

Rábade, S. (1996). Guillermo de Ockham y la Filosofia del siglo XIV. Madrid: Instituto "Luis Vives" de Filosofia.

San Buenaventura. (1945 y siguientes). Obras Completas (Vol. 6). Madrid: Biblioteca de Autores Cristianos -B.A.C.

San Buenaventura. (1993). Reducción de las Ciencias a la Teología. En J. A. Merino, Historia de la Filosofia Franciscana. Madrid: B.A.C.

Uribe, F. (Enero-junio de 2011). Tareas de la teologìa franciscana en el futuro. El Ágora USB, 11(1), 207-217. Obtenido de http://revistas.usb.edu.co/index.php/Agora/ article/view/389/150 